American Journal of Applied Sciences 6 (5): 857-861, 2009

ISSN 1546-9239

(C) 2009 Science Publications

\title{
Antifungal Activity of Essential Oils from Some Medicinal Plants of Iran against Alternaria alternate
}

\author{
${ }^{1}$ I. Hadizadeh, ${ }^{2}$ B. Peivastegan and ${ }^{3}$ H. Hamzehzarghani \\ ${ }^{1}$ Department of Plant Protection, \\ Collage of Agriculture, Shahid Chamran University, Postal code: Ahvaz, Iran \\ ${ }^{2}$ Department of Agronomy, \\ Collage of Agriculture, Islamic Azad University, Shoushtar Branch, Iran \\ ${ }^{3}$ Department of Plant Protection \\ College of Agriculture, Badjgah, Shiraz University, Shiraz, Postal Code: 71444-65186, Iran
}

\begin{abstract}
Problem statement: Increasing public concern over the level of pesticide residues in food especially fresh produce has built up adequate pressure for scientists to look for less hazardous and environmentally safer compounds for controlling post harvest diseases. Essential oils as registered food grade materials have the potential to be applied as alternative anti-fungal treatments for fresh fruits and vegetables. Approach: We present in this study, the identification of the essential oils with antifungal activity from some medicinal plants of Iran (nettle (Urtica dioica L.), thyme (Thymus vulgaris L.), eucalyptus (Eucalyptus spp.), Rue (Ruta graveolens L.) and common yarrow (Achillea millefolium L.)), and their potential application as "generally regarded as safe" antifungal compounds against Alternaria alternate on tomato as a model pathosystem. Results: Both the nettle and the thyme oils exhibited antifungal activity against A. alternata. The thyme oil exhibited a lower degree of inhibition 68.5 and $74.8 \%$ at 1500 and 2000 ppm, respectively. Spore germination and germ tube elongation of the pathogens in potato dextrose broth was strongly reduced in the presence of $1500 \mathrm{ppm}$ of the nettle oil. The same concentration of this oil reduced the percentage of decayed tomatoes. The experiments on reducing the development of natural tomato rot gave similar results. Conclusions: Application of essential oils for postharvest disease control of fresh produce, as a novel emerging alternative to hazardous anti-fungal treatments will allow a safer and environmentally more acceptable management of postharvest diseases.
\end{abstract}

Key words: Nettle, thyme, eucalyptus, rue, common yarrow, Alternaria rot

\section{INTRODUCTION}

Tomato (Lycopersicon esculentum) is an important commercial crop in the world. Nutritional values of tomato make it a widely accepted vegetable by consumers. Nevertheless, tomato is a very perishable vegetable with a short shelf-life and high susceptibility to fungal disease. During prolonged storage, tomato is susceptible to postharvest disease caused by various pathogenic fungi. Alternaria alternata is a saprophytic pathogen of tomato causing post harvest losses at high frequency ${ }^{[2]}$. The main method to control Alternaria rot and other postharvest diseases is based on application of synthetic chemical products. However, nowadays consumers demand less use of synthetic chemicals and still expect food to be free from blemishes, microbial growth, toxins and other quality deteriorating factors ${ }^{[9]}$.

Application of essential oil is a very attractive method for controlling postharvest diseases. Production of essential oils by plants is believed to be predominantly a defense mechanism against pathogens and pests and indeed, essential oils have been shown to possess antimicrobial and antifungal properties ${ }^{[1]}$. Essential oils and their components are gaining increasing interest because of their relatively safe status, their wide acceptance by consumers and their exploitation for potential multi-purpose functional use [12]. Essential oils are made up of many different volatile compounds and the composition of the oil quite often varies between species ${ }^{[10]}$. It is difficult to

Corresponding Author: H. Hamzehzarghani, Department of Plant Protection, College of Agriculture, Shiraz University, Shiraz, Postal Code: 71444-65186 Iran, Phone: +1198-711-613-8322, Fax: +1198-711-228-6087, 
associate the antifungal activity to single compounds or classes of compounds. It seems that the antifungal and antimicrobial effects are the result of many compounds acting synergistically ${ }^{[4]}$. Thus, there would be negligible chance of development of resistant races of fungi after application of essential oils to fruit and vegetables. As a consequence essential oils are one of the most promising candidate groups of natural compounds for the development of safer antifungal agents.

The objective of this study was to investigate the inhibitory effects of essential oils extracted from five plant species against A. alternata and to evaluate the potential application of essential oils to control Alternaria rot of stored tomatoes.

\section{MATERIALS AND METHODS}

Extraction of essential oil: Steam distillation was used for the extraction of the essential oil. The air-dried plants material weighing $200 \mathrm{~g}$ was placed in round bottom flask containing $150 \mathrm{~mL}$ water and distilled. The distillate was saturated with $\mathrm{NaCl}$ and transferred to a separator funnel where it was extracted with diethyl ether. The organic phase was recovered and concentrated on a steam bath to yield $2.8 \mathrm{~g} / 100 \mathrm{~g}$ plants material. The essential oils were stored in bottles at $4^{\circ} \mathrm{C}$.

Plant material: The plant materials were collected from Research Institute of Forests and Rangelands, Ahwaz, Iran, in 2007. Voucher specimen was deposited in the Botany Department of Science College Shahid Chamran University. Plant material were freed from foreign materials and carefully rubbed between soft cloths to remove dust.

Isolation of fungi: Fungi were isolated from deteriorating tomato fruits purchased from the open market using Potato Dextrose Agar (PDA) containing $100 \mathrm{mg}$ chloramphenicol per $\mathrm{ml}$ and identified with the aid of the appropriate taxonomic keys ${ }^{[3]}$. The isolates were maintained on PDA slants at $4^{\circ} \mathrm{C}$ till needed.

\section{In vitro antifungal assay:}

In vitro contact assay: $\mathrm{PDA}$ was autoclaved and cooled in a water bath to $40^{\circ} \mathrm{C}$. The essential oils were mixed with sterile molten PDA to obtain final concentrations 0, 100, 500, 1000, 1500 and 2000 ppm. The PDA was poured into $90 \mathrm{~mm}$ Petri plates $(15 \mathrm{~mL}$ plate $^{-1}$ ) that were then inoculated with $6 \mathrm{~mm}$ plugs from 7-days-old cultures. Three replicates were used per treatment. Plates were incubated for 7 days at $28^{\circ} \mathrm{C}$. Fungal growth was recorded after 7 days. Growth inhibition was calculated as the percentage of inhibition of radial growth relative to the control. Experiments were performed three times.

Spore germination assay: The effect of nettle oil on spore germination and germ tube elongation of the pathogens were tested in Potato Dextrose Broth (PDB). Nettle oil was added to a $10 \mathrm{ml}$ glass tube containing 5 $\mathrm{mL}$ PDB to obtain final concentrations 0, 100, 500, 1000, 1500 and $2000 \mathrm{ppm}$. At the same time, aliquots $(100 \mu \mathrm{L})$ of spore suspensions $\left(1 \times 10^{7}\right.$ spores $\left.\mathrm{mL}^{-1}\right)$ of A. alternata were added to each tube. After $20 \mathrm{~h}$ of incubation at $28^{\circ} \mathrm{C}$ on a rotary shaker $(200 \mathrm{rpm})$, at least 100 spores per replicate were observed microscopically to determine germination rate and germ tube length ${ }^{[8]}$. Experiments were repeated three times.

In vivo applicability of nettle oil in control of post harvest fungal rot of tomatoes:

Effects of nettle oil on decay development in artificially inoculated and wounded fruits: Fruits were selected for freedom of injuries and infections and were placed in $1.5 \mathrm{~L}$ plastic boxes. Fruits were dipped in the solution of $1 \%$ sodium hypochlorite for $2 \mathrm{~min}$, rinsed with tap water and air-dried before wounding. Tomatoes were wounded with a sterile puncher to make one uniform $2 \mathrm{~mm}$ deep by 5 -mm wide wound on their peel at the equatorial region. Aliquots of $20 \mu \mathrm{L}$ of 500 , 1000, 1500 and 2000 ppm nettle oil and sterile distilled water (control) was pipetted into each wound site. After $0.5 \mathrm{~h}, 10 \mu \mathrm{L}$ of conidial suspension of A. alternata $\left(5 \times 10^{4}\right.$ spores $\left.\mathrm{mL}^{-1}\right)$ was pipetted into each wound. Treated tomatoes were stored at $20^{\circ} \mathrm{C}$. The percentage of infected fruits was recorded after 5 days of incubation. Each treatment was replicated three times with 20 fruits per replicate.

Effects of nettle oil on naturally infected development in unwounded fruit: The concentration of the nettle oils were prepared by dissolving the requisite amounts in $25 \mathrm{~mL}$ of $0.05 \%$ Tween- 80 and then mixing with $475 \mathrm{~mL}$ of sterile distilled water. The control sets were prepared similarly using equal amounts of sterilized water in place of the essential oil. Tomatoes were dipped into the solutions for $1 \mathrm{~min}$ at room temperature and air dried. Fruits were dipped into sterile distilled water, which served as control and air dried. Treated tomatoes were stored at $20^{\circ} \mathrm{C}$ for 21 days. The percentage of infected fruits was recorded when about $50 \%$ tomatoes of the control had decayed. Each treatment was replicated three times with 20 fruits per replicate.

Statistical analysis: Statistical analysis of the data obtained in the present study was carried out in a 
completely randomized design layout with three replicates using Statgraphics plus 2.0. Where a significant difference between means was verified based on ANOVA, the comparison of means of different treatments was performed using Tukey's test at $\mathrm{p}=0.05$.

\section{RESULTS}

In vitro antifungal assay:

In vitro contact assay: The inhibitory effects of nettle, thyme, eucalyptus, Rue and common yarrow oils against $A$. alternata are shown in Table 1 . Nettle oil at $1500 \mathrm{ppm}$ showed potent and completely inhibitory effect on the radial growth of A. alternate. The oil of thyme exhibited a moderate to high antifungal activity against the pathogen tested, ranging from $68.5-74.8 \%$ at 1500 and $2000 \mathrm{ppm}$, respectively.

Low antifungal effects of Rue and eucalyptus oil were observed against on A. alternata in vitro contact assay with fungal mycelial growth inhibition percentage from 7.3-30.6 and 8.7-20.7\%, respectively. Common yarrow oil did not affect the growth of A. alternata.

Spore germination assay: According to the results given in the Table 2, spore germination of pathogens in PDB was strongly inhibited in the presence of nettle oil. There was a significant inhibition $(p<0.05)$ of fungal spore germination by different concentrations of essential oil.

Table 1: The inhibitory effects of essential oils on A. alternate Percentage of inhibition

\begin{tabular}{|c|c|c|c|c|c|}
\hline $\begin{array}{l}\text { Essential } \\
\text { oil }\end{array}$ & 100 & 500 & 1000 & 1500 & $2000(\mathrm{ppm})$ \\
\hline Nettle oil & $14.3 \pm 1.5 \mathrm{a}^{\mathrm{a}}$ & $43.9 \pm 0.7 b$ & $65.9 \pm 2.3 c$ & $100 \pm 0 \mathrm{~d}$ & $100.0 \pm 0 \mathrm{~d}$ \\
\hline Thyme oil & $10.6 \pm 1.8 \mathrm{a}$ & $31.5 \pm 2.2 b$ & $43.6 \pm 1.6 b$ & $68.5 \pm 0.4 \mathrm{c}$ & $74.80 \pm 0.84 \mathrm{c}$ \\
\hline $\begin{array}{l}\text { Eucalyptus } \\
\text { oil }\end{array}$ & $-\mathrm{b}$ & - & $7.30 \pm 0.3 \mathrm{a}$ & $16.0 \pm 1.4 \mathrm{a}$ & $30.60 \pm 2.6 b$ \\
\hline Rue oil & - & - & $8.70 \pm 2.3 \mathrm{a}$ & $15.9 \pm 0.8 \mathrm{a}$ & $20.70 \pm 1.3 \mathrm{a}$ \\
\hline $\begin{array}{l}\text { Common } \\
\text { yarrow oil }\end{array}$ & - & - & - & - & - \\
\hline
\end{tabular}

${ }^{\mathrm{a}}$ : Values are the mean of three replicates $\pm S E$; ${ }^{\mathrm{b}}$ : Indicates ineffective on microorganism

Table 2: Effect of different concentrations of nettle oil on spore germination and germ tube elongation of A. alternata

\begin{tabular}{lll}
\hline Treatments & Spore germination $(\%)$ & Germ tube length $(\mu \mathrm{m})$ \\
\hline Control & $100 \pm 0 \mathrm{a}^{\mathrm{a}}$ & - \\
$100 \mathrm{ppm}$ & $59.6 \pm 1.5 \mathrm{~b}$ & $98.1 \pm 2.3 \mathrm{a}$ \\
$500 \mathrm{ppm}$ & $31.5 \pm 3.2 \mathrm{c}$ & $83.9 \pm 0.8 \mathrm{~b}$ \\
$1000 \mathrm{ppm}$ & $12.6 \pm 0.6 \mathrm{~d}$ & $53.2 \pm 1.7 \mathrm{c}$ \\
$1500 \mathrm{ppm}$ & $6.4 \pm 1.3 \mathrm{e}$ & $30.7 \pm 2.3 \mathrm{~d}$ \\
$2000 \mathrm{ppm}$ & $6.1 \pm 0.9 \mathrm{e}$ & $28.2 \pm 2.7 \mathrm{e}$ \\
\hline
\end{tabular}

${ }^{a}$ : Values are the mean of three replicates \pm SE. Where the letters are the same, there is no significant difference between the means of different concentrations
Above $93 \%$ inhibition of fungal spore germination was observed at $1500 \mathrm{ppm}$ concentration of nettle oil. The germ tube length was only $2.8 \mu \mathrm{m}$ at $1500 \mathrm{ppm}$. Spores of A. alternata all germinated after $20 \mathrm{~h}$ incubation at $28^{\circ} \mathrm{C}$ in PDB without nettle oil. The germ tubes were long and entwined so that germ tube length could not be determined.

In vivo applicability of nettle oil in control of post harvest fungal rot of tomatoes:

Effects of nettle oil on rot development in artificially inoculated and wounded fruits: The results shown in Fig. 1 indicate that when wounded tomatoes were treated with nettle oil, all concentrations (except 100 ppm) significantly inhibited A. alternata on tomatoes stored at $20^{\circ} \mathrm{C}$ for 5 days $(\mathrm{p}<0.05)$. The percentage of decayed tomatoes treated by $1500 \mathrm{ppm}$ nettle oil was reduced by $46.42 \%$ compared to the control. Treatment with nettle oil did not cause any visible disorders and off-odor to the fruits after 5 days of storage.

Effects of nettle oil on naturally infected development in unwounded fruit: The results show that when unwounded tomatoes were treated with nettle oil, all concentrations significantly inhibited $A$. alternata on tomatoes stored at $25^{\circ} \mathrm{C}$ for 5 days $(p<0.05)$ (Fig. 2). The percentage of decayed tomatoes treated by $1500 \mathrm{ppm}$ nettle oil was reduced by $41.6 \%$ compared to the control.

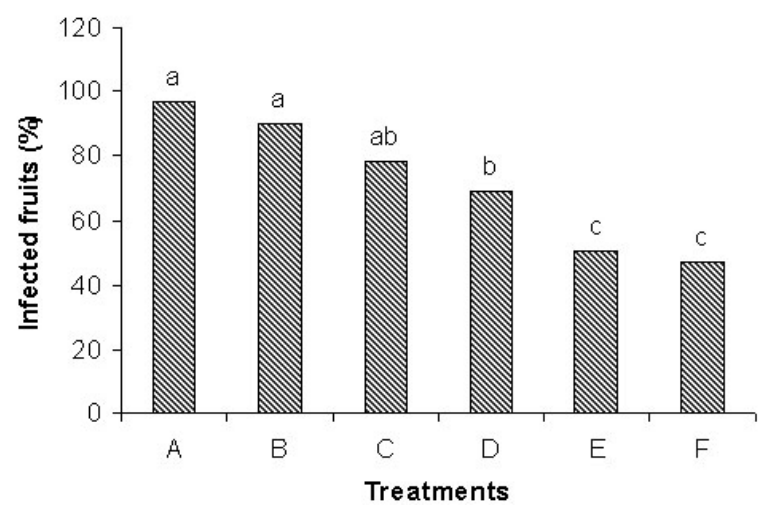

Fig. 1: Inhibition of $A$. alternata on artificially inoculated and wounded tomatoes by nettle oil: (A) Control, (B) $100 \mathrm{ppm}$, (C) $500 \mathrm{ppm}$, (D) $1000 \mathrm{ppm}$, (E) $1500 \mathrm{ppm}$ and (F) $2000 \mathrm{ppm}$ significant differences $(\mathrm{p}<0.05)$ between means are indicated by letters above histogram bars. Where the letters are the same, there is no significant difference between different treatments 


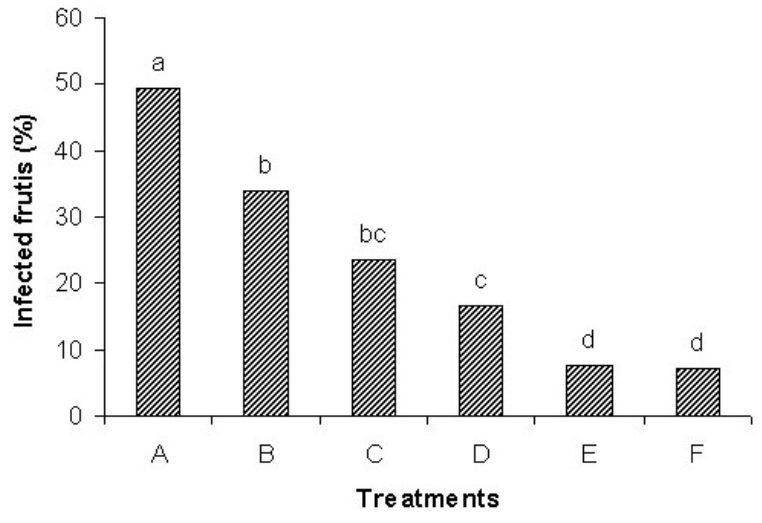

Fig. 2: Effects of nettle oil on naturally infected development in unwounded tomatoes: (A) Control, (B) 100 ppm, (C) 500 ppm, (D) 1000 ppm, (E) $1500 \mathrm{ppm}$ and (F) $2000 \mathrm{ppm}$ significant differences $(\mathrm{p}<0.05)$ between means are indicated by letters above histogram bars. Bars with the same letters show are not significantly difference.

\section{DISCUSSION}

In an attempt to reduce the use of synthetic pesticides, over the past two decades extensive investigations have been made into the possible exploitation of plant compounds as natural commercial products, that are safe for humans and the environment $^{[7]}$ Although essential oils from various wild plants have been reported in the past to be effective against a wide range of micro-organisms in $v$ itro ${ }^{[6]}$, these essential oils failed to inhibit pathogen growth in vivo ${ }^{[5]}$ and failed to control diseases under field conditions in most cases. Although in vitro screening of plant extracts is an important first step in identifying plants with potential application in agriculture, in vivo confirmation of this potential is essential in the search for plant derived preparations with the potential to be commercialized ${ }^{[13]}$.

The ability of five essential oils to inhibit $A$. alternata was evaluated in vitro contact assays. The most active oil was nettle oil followed by thyme oil. The antifungal efficacy appears to relate to the chemical composition of essential oils. The spore germination assay demonstrated the inhibitory effect of nettle oil on the spores of A. alternata.

The in vivo efficacy of nettle oil was studied in this study. The results showed nettle oil significantly reduced the rot not only in artificially inoculated and wounded fruits but also in unwounded fruit. Although the percentage of infected fruits in tomatoes treated by nettle oil was significantly lower than those in control, the inhibition by nettle oil in tomatoes was not as dramatic as that in plates. In general, levels of essential oils and their compounds necessary to inhibit microbial growth are higher in foods than in culture media. This is due to interactions between phenolic compounds and the food matrix ${ }^{[11]}$. Because essential oils are made up of many different volatile compounds, the post storage residual levels are anticipated to be low. Whether the effective concentrations of nettle oil would affect the flavor of tomatoes, calls for more work on studying the quality parameters of tomatoes after storage.

\section{CONCLUSION}

In conclusion, examination of various concentrations of thyme and nettle oils on A. alternata in this study showed promising prospects for the utilization of natural plants or their oils and extracts in post harvest disease control. In vivo experiments showed that nettle oil could reduce postharvest diseases on tomatoes caused by A. alternata. So essential oils can be used as a potential source of sustainable ecofriendly botanical fungicides, after successful completion of wide range trials.

\section{REFERENCES}

1. Ahmet, C., K. Saban, K. Hamdullah and K. Ercan, 2005. Antifungal properties of essential oil and crude extracts of Hypericum linarioides Bosse. Biochem. Syst. Ecol., 33: 245-256. DOI: 10.1016/j.bse.2004.08.006.

2. Akhtar, K.P., M. Matin, J.H. Mirza, A.S. Shakir and M. Rafique, 1994. Some studies on the post harvest diseases of tomato fruits and their chemical control. Pak. J. Phytopathol., 6: 125-129. http://www.phtnet.org/research/viewabstract.asp?re search_id=wk280.

3. Ainsworth, G.C., F.K. Sparrow and A.S. Sussman, 1973. The Fungi Vol. IVA. A Taxonmic Review with Keys: Ascomycetes and Fungi Imperfection. Academic Press, London, pp: 375

4. Bagamboula, C.F., M. Uyttendaele and J. Debevere, 2004. Inhibitory effect of thyme and basil essential oils, carvacrol, thymol, estragol, linalool and p-cymene towards Shigella sonnei and S. flexneri. Food Microbiol., 21: 33-42. DOI: 10.1016/S0740-0020(03)00046-7.

5. Benner, J.P., 1993. Pesticidal compounds from higher plants. Pestic. Sci., 39: 95-102.

http://md1.csa.com/partners/viewrecord.php?reque ster $=$ gs \& collection $=$ ENV \&recid $=3553446 \& q=\&$ ui $\mathrm{d}=793352250 \&$ setcookie $=$ yes. 
6. Chang, H., Y. Cheng, C. Wu, S. Chang, T. Chang and Y. Su, 2008. Antifungal activity of essential oil and its constituents from Calocedrus macrolepis var. formosana Florin leaf against plant pathogenic fungi. Bioresour. Technol., 99: 6266-6270 DOI: 10.1016/j.biortech.2007.12.005.

7. Daayf, F., A. Schmitt and R.R. Bélanger, 1995. The effects of plant extracts of Reynoutria sachalinensis on powdery mildew development and leaf physiology of long English cucumber. Plant Dis., 79: 577-580.

http://apsnet.org/pd/PDFS/1995/PlantDisease79n06 577.PDF.

8. Droby, S., M.E. Wisniewski, L. Cohen, B. Weiss, D. Touitou and Y. Eilam et al., 1997. Influence of $\mathrm{CaCl} 2$ on Penicillium digitatum, grapefruit peel tissue and biocontrol activity of Pichia guilliermondii. Phytopathology, 87: 310-315. http://apsjournals.apsnet.org/doi/abs/10.1094/PHY TO.1997.87.3.310.

9. Lingk, W., 1991. Health risk evaluation of pesticide contamination in drinking water. Gesunde Pflangen, 43: 21-25.

http://www.fao.org/agris/search/display.do?f=./199 1/v1713/DE91U0034.xml;DE91U0034.
10. Mishra, A.K. and N.K. Dubey, 1994. Evaluation of some essential oils for their toxicity against fungi causing deterioration of stored food commodities. Applied Environ. Microbiol., 60: 1101-1105. http://aem.asm.org/cgi/reprint/60/4/1101.

11. Nychas, G.E. and C.C. Tassou, 2000. Traditional Preservatives-Oils and Spices. In Encylopedia of Food Microbiology, Robinson, R.K., C.A. Batt and P.D. Patel (Eds.). Academic Press, London, UK., pp: 1717-1722. ISBN: 012227070312.

12. Jobling, J. 2000. Essential Oils: A new idea for postharvest disease control. Good Fruit and Vegetables Magazine, 11: 50. http://www.postharvest.com.au/GFV_oils.PDF.

13. Tegegne, G. and J.C. Pretorius, 2007. In vitro and in vivo antifungal activity of crude extracts and powdered dry material from Ethiopian wild plants against economically important plant pathogens. Biocontrol, 52: 887-888. DOI: 10.1007/s10526007-9088-y. 